\title{
Systematic review of randomized controlled trials of therapeutic hypothermia as a neuroprotectant in post cardiac arrest patients
}

\author{
Ka Wai Cheung, MD; ${ }^{*}$ Robert S. Green, BSc, MD; ${ }^{* \dagger}$ Kirk D. Magee, MD, MSc
}

\begin{abstract}
Objective: Several randomized controlled trials have suggested that mild induced hypothermia may improve neurologic outcome in comatose cardiac arrest survivors. This systematic review of randomized controlled trials was designed to determine if mild induced hypothermia improves neurologic outcome, decreases mortality, or is associated with an increased incidence of adverse events. Data sources: The following databases were reviewed: Cochrane Controlled Trials Register (Issue 4, 2005), MEDLINE (January 1966 to November 2005), EMBASE (1980 to November 2005), CINAHL (1982 to November 2005) and Web of Science (1989 to November 2005). For each included study, references were reviewed and the primary author contacted to identify any additional studies.

Study selection: Studies that met inclusion criteria were randomized controlled trials of adult patients ( $>18$ years of age) with primary cardiac arrest who remained comatose after return of spontaneous circulation. Patients had to be randomized to mild induced hypothermia $\left(32^{\circ} \mathrm{C}-34^{\circ} \mathrm{C}\right)$ or normothermia within 24 hours of presentation. Only studies reporting pre-determined outcomes including discharge neurologic outcome, mortality or significant treatment-related adverse events were included. There were no language or publication restrictions.

Data synthesis: Four studies involving 436 patients, with 232 cooled to a core temperature of $32^{\circ} \mathrm{C}-34^{\circ} \mathrm{C}$ met inclusion criteria. Pooled data demonstrated that mild hypothermia decreased inhospital mortality (relative ratio $[\mathrm{RR}] 0.75 ; 95 \%$ confidence interval $[\mathrm{Cl}], 0.62-0.92$ ) and reduced the incidence of poor neurologic outcome (RR $0.74 ; 95 \% \mathrm{Cl}, 0.62-0.84$ ). Numbers needed to treat were 7 patients to save 1 life, and 5 patients to improve neurologic outcome. There was no evidence of treatment-limiting side effects.

Conclusions: Therapeutically induced mild hypothermia decreases in-hospital mortality and improves neurologic outcome in comatose cardiac arrest survivors. The possibility of treatment-limiting side effects cannot be excluded.
\end{abstract}

Key words: cardiac arrest; induced hypothermia; systematic review

RÉSUMÉ

Objectif : Plusieurs essais comparatifs randomisés ont suggéré qu'une légère hypothermie provoquée peut améliorer le résultat clinique chez les victimes d'arrêt cardiaque dans le coma. La

From the *Department of Emergency Medicine, and the tDepartment of Internal Medicine, Division of Critical Care Medicine, Queen Elizabeth II Health Sciences Centre, Dalhousie University, Halifax, NS

Received: Apr. 3, 2006; revisions received: July 27, 2006; accepted: Aug. 2, 2006

This article has been peer reviewed.

Can J Emerg Med 2006;8(5):329-37 
présente étude méthodique d'essais comparatifs randomisés a été conçue dans le but de déterminer si une légère hypothermie provoquée améliore le devenir neurologique, réduit la mortalité ou est associée à une augmentation de l'incidence des effets indésirables.

Sources des données: Les banques de données suivantes furent consultées : Cochrane Controlled Trials Register (numéro 4, 2005), MEDLINE (de janvier 1966 à novembre 2005), EMBASE (de 1989 à novembre 2005), CINAHL (de 1982 à novembre 2005) et Web of Science (de 1989 à novembre 2005). Pour chaque étude incluse, les références furent examinées et l'auteur principal fut contacté afin d'identifier des études supplémentaires.

Sélection des études : Les études qui répondaient aux critères d'inclusion étaient des essais comparatifs randomisés auprès de patients adultes (> 18 ans) victimes d'un arrêt cardiaque qui sont demeurés dans le coma après le retour de la circulation spontanée. Les patients devaient avoir été randomisés dans le groupe d'hypothermie provoquée $\left(32-34^{\circ} \mathrm{C}\right)$ ou dans celui de la normothermie dans les 24 heures suivant leur arrivée. Seules les études indiquant les résultats cliniques prédéterminés, comprenant l'état neurologique au moment du congé, la mortalité ou les effets indésirables importants liés au traitement furent incluses. II n'y avait aucune restriction quant à la langue ou à la publication.

Synthèse des données : Quatre études incluant 436 patients, dont 232 furent refroidis à une température centrale entre $32-34^{\circ} \mathrm{C}$ répondaient aux critères d'inclusion. Les données totalisées démontraient qu'une légère hypothermie réduisait la mortalité à l'hôpital (risque relatif [RR] 0,75 ; intervalle de confiance [IC] $95 \%, 0,62-0,92$ ) et diminuait l'incidence des résultats neurologiques négatifs (RR 0,74; IC $95 \%, 0,62-0,84$ ). Le nombre nécessaire de patients à traiter était de sept patients pour sauver une vie, et de cinq patients pour améliorer le devenir neurologique. II n'y avait aucune preuve d'effets secondaires limitant le traitement.

Conclusions: L'hypothermie provoquée à des fins thérapeutiques réduit la mortalité à l'hôpital et améliore le devenir neurologique chez les victimes d'arrêt cardiaque dans le coma. La possibilité d'effets secondaires limitant le traitement ne peut être exclue.

\section{Introduction}

\section{Background}

Out-of-hospital cardiac arrests are common, with an estimated annual incidence of 36 to 128 per 100000 people in industrialized countries. ${ }^{1}$ It is associated with a $65 \%-95 \%$ mortality rate, and the majority of patients who are resuscitated have a poor neurologic outcome..$^{2-5}$ Efforts to identify a treatment modality with a beneficial effect on recovery from anoxic brain injury after cardiac arrest have been disappointing. ${ }^{6-9}$ Therapeutic hypothermia may provide beneficial effects for patients who are resuscitated from cardiac arrest by reducing cerebral oxygen demand, ${ }^{10-13}$ intracranial pressure, ${ }^{14}$ excitatory neurotransmitter production, ${ }^{15}$ and oxygen free radical formation/accumulation. ${ }^{16}$ However, there has also been concern that mild hypothermia may increase infection rate, ${ }^{17-19}$ induce coagulopathy, ${ }^{20,21}$ and depress cardiac function. ${ }^{19}$

\section{Importance}

Recently, prospective randomized controlled trials have suggested that mild induced hypothermia (core temperature $32^{\circ} \mathrm{C}-34^{\circ} \mathrm{C}$ ) for $12-24$ hours may be beneficial in resuscitated post cardiac arrest patients with anoxic brain injury. However, therapeutic hypothermia in cardiac arrest survivors remains controversial due to the relatively small number of total study patients, low enrolment of eligible patients and a perceived difficulty in applying this mode of therapy.

\section{Objectives}

This systematic review will assess whether mild induced hypothermia decreases mortality and improves neurologic outcomes in comatose survivors resuscitated from cardiac arrest. Furthermore, we will also determine whether mild hypothermia in this setting causes significant adverse events.

\section{Methods}

\section{Data source}

A comprehensive search of the Cochrane Controlled Trials Register (Issue 4, 2005), MEDLINE (January 1966 to November 2005), EMBASE (1980 to November 2005), CINAHL (1982 to November 2005), and Web of Science (1989 to November 2005) was conducted to identify potential studies. There were no language or publication restrictions. The search consisted of the following terms: cardiac arrest, heart arrest, cardiopulmonary resuscitation, hypothermia, and induced hypothermia. Reference lists of 
all available primary studies and review articles were assessed to identify potentially relevant citations. Inquiries regarding other published or unpublished studies known and/or supported by the authors of the included studies were performed. In addition, personal contact with colleagues, collaborators and other investigators working in the field of hypothermia in cardiac arrest survivors was made to identify potentially relevant studies.

All trials that appeared relevant on the basis of "Title," "Abstract" or "MeSH Headings" were selected for full review by one reviewer (K.W.C.). From these potentially relevant articles and using an inclusion and exclusion criteria checklist, 2 reviewers (K.W.C. and R.G.) independently selected trials based on the full text for inclusion into the review. Agreement was measured using simple agreement and kappa statistics. ${ }^{22}$ Disagreement was resolved by consensus or third party adjudication.

\section{Study selection}

Inclusion criteria were any study that was a randomized or quasi-randomized controlled clinical trial of adults $(>18$ years of age) who had a primary cardiac arrest and were comatose (Glasgow Coma Scale score $<8$ ) after return of spontaneous circulation (ROSC). Other inclusion criteria included patient randomization to mild induced hypothermia $\left(32^{\circ} \mathrm{C}-34^{\circ} \mathrm{C}\right)$ versus normothermia within 24 hours of presentation and assessment and description of neurologic outcome or mortality.

\section{Validity assessment}

Two reviewers (K.W.C., K.M.) who were unblinded to authors and study results independently assessed methodological quality of each included study by using 2 methods: the Cochrane concealment of allocation approach ${ }^{23}$ and the Jadad criteria. ${ }^{24}$ The Cochrane approach assesses allocation concealment using the following principles: grade $\mathrm{A}$ - adequate concealment, grade B - uncertain concealment, and grade $\mathrm{C}$ - clearly inadequate concealment. In addition, each study was assessed using a previously validated $0-5$ scale described by Jadad. The Jadad Scale determines the quality of clinical trials based on study randomization, presence of double-blinding, the description of withdrawals and the process of randomization and blinding.

\section{Data abstraction}

A priori outcomes included in-hospital mortality, 6-month mortality, discharge neurologic outcome, as well as hemodynamic instability, dysrrhythmia, infection or sepsis, and coagulopathy. "Good" neurologic outcome was defined as either no disability or mild-to-moderate disability, and "poor" neurologic outcome included those with more severe disability. Data from all included studies were extracted by one reviewer (K.W.C.) and double entered to ensure data accuracy into Review Manager (Version 4.1; Oxford, UK).

\section{Quantitative data synthesis}

For dichotomous variables, individual and pooled statistics were calculated as relative risks (RRs) with 95\% confidence intervals (95\% CIs). For continuous outcomes, individual and pooled statistics were calculated as weighted mean differences or standardized mean differences with 95\% CIs. A random effects model was to be used if more than 5 trials were pooled. When fewer trials or no heterogenity was identified, a fixed effects model was employed. Random effects modelling takes into account both withinstudy variability and between-study variation, and fixed effect modelling assumes that all variance come from within-study.

Heterogeneity refers to the differences in results of the individual studies included in the systematic review. Heterogeneity was assessed using the $\mathrm{I}^{2}$ statistic ${ }^{25}$ and the Breslow-Day $\chi^{2}$ test ${ }^{26}$ with significance being denoted by a $p$ value $<0.10$. In the setting of significant heterogeneity, it was decided a priori to conduct a sensitivity analysis with the groups being divided based on methodological quality. Those studies with a Jadad Scale score of $\geq 3$ were to be compared with those with a score $<3$. Although extensive efforts were made to identify unpublished studies, funnel plots were analyzed for evidence of publication bias. ${ }^{27}$

\section{Results}

\section{Selection of studies}

In total, 2131 potentially relevant articles were screened for retrieval. Forty-seven articles (or abstracts, when full articles were unavailable) were retrieved and reviewed independently by 2 investigators (K.W.C., R.G.). This first review yielded 4 studies $^{28-31}$ that met inclusion criteria. The agreement kappa statistic for study inclusion was good $(\kappa$ $=0.85$ ). A review of the reference lists of these selected articles yielded 1 potentially relevant article. ${ }^{15}$ However, this last article was subsequently excluded as not all patients had ROSC. After contacting the authors of all the included studies, no further relevant studies were identified, resulting in 4 studies of 436 patients being included in the review (Fig. 1). The funnel plot demonstrates asymmetry in the area of small negative trials, indicating that unpublished negative trials might exist that we failed to identify for inclusion in this review. 


\section{Study characteristics}

Table 1 summarizes the 4 included studies. The Hypothermia after Cardiac Arrest (HACA) Study ${ }^{30}$ and the Bernard and colleagues study ${ }^{31}$ were large multicentre trials, and the
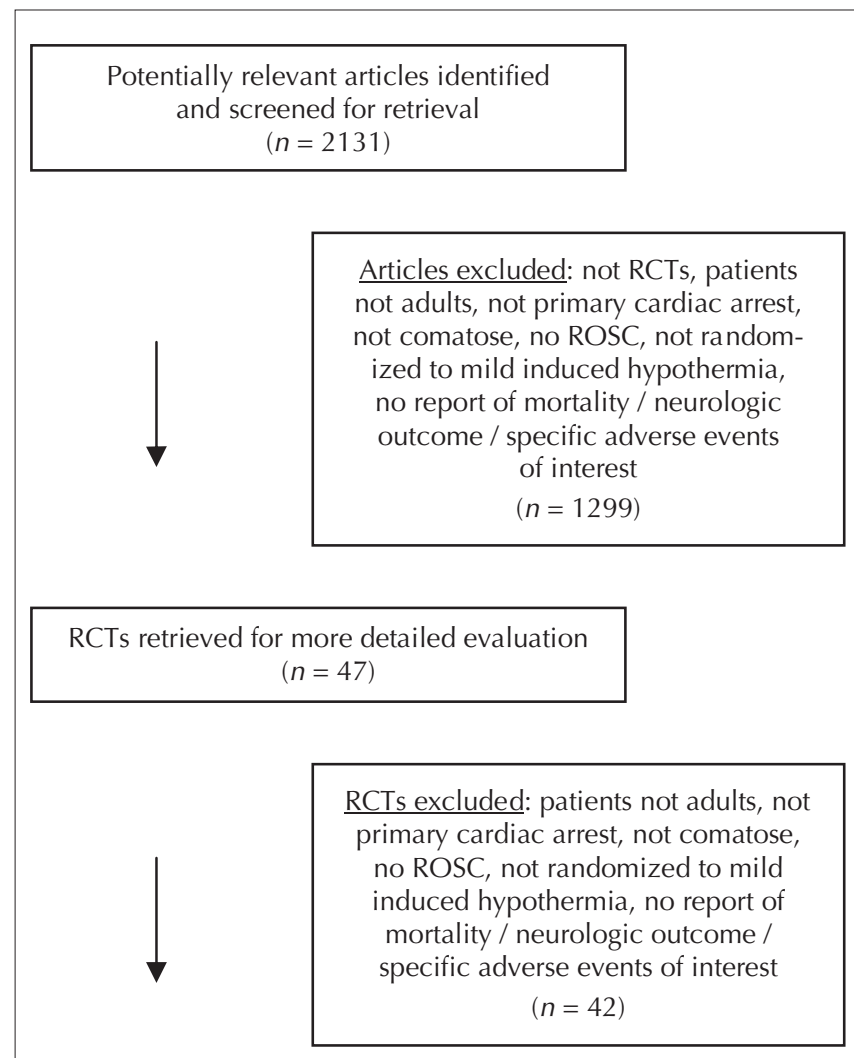

Potentially appropriate RCTs to be included in systematic review $(n=4)$

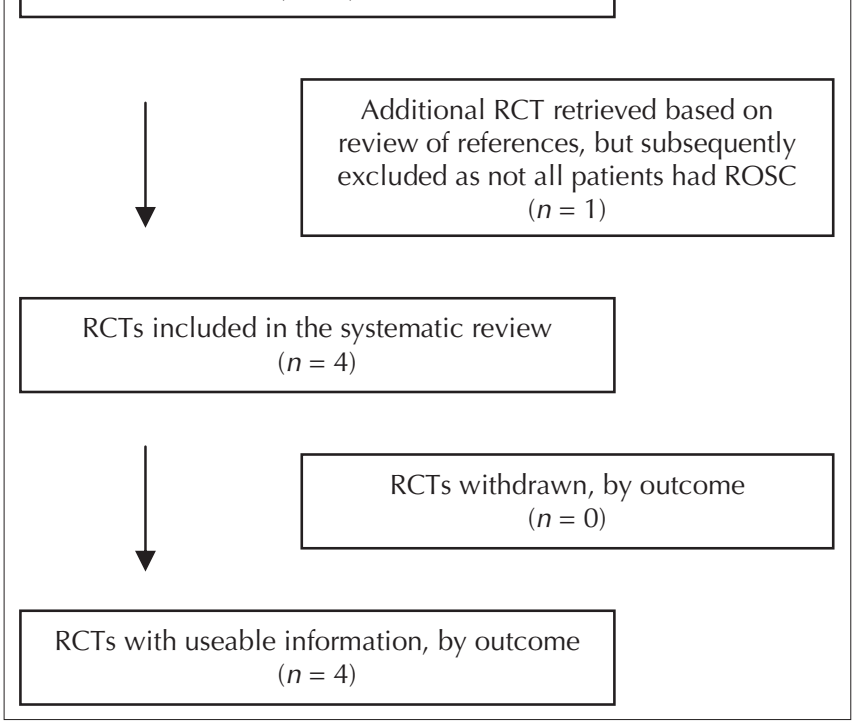

Fig. 1. Flow diagram. $\mathrm{RCT}=$ randomized controlled trial; ROSC $=$ return of spontaneous circulation
Hachimi-Idrissi and coworkers ${ }^{29}$ and Mori and associates ${ }^{28}$ studies were smaller, single-centre trials. The HachimiIdrissi and coworkers study was a feasibility study: once mild hypothermia was attained, the cooling helmet was removed. The inclusion criteria for presenting cardiac rhythms differed between the trials; the HACA Study ${ }^{30}$ and Bernard and colleagues study ${ }^{31}$ included only patients presenting with ventricular arrhythmias, while HachimiIdrissi and coworkers enrolled only patients presenting with asystole or pulseless electrical activity (PEA). The initial rhythm was unclear in patients enrolled in the Mori and associates study. Greater than $94 \%$ of included patients had a witnessed cardiac arrest in the HACA and Bernard and colleagues studies, and only approximately $50 \%$ of patients had a witnessed cardiac arrest in the Hachimi-Idrissi and coworkers study. The median time from collapse to ROSC ranged from 21 to 34 minutes in the 3 trials reporting this variable..$^{29-31}$

There was dichotomy in the methodologic quality of the included studies. Two studies had adequate concealment of allocation with Jadad Scale scores of 3 (Table 2). In the other 2 studies, concealment of allocation was unclear or inadequate. Both of these studies had Jadad scores of 1.

\section{Sensitivity analyses}

Three studies reported in-hospital mortality. ${ }^{29-31}$ Only 1 of these studies showed a definite decrease in in-hospital mortality. ${ }^{30}$ However, when data from the 3 studies were pooled, mild induced hypothermia reduced the overall incidence of in-hospital mortality compared with treatment with normothermia (RR, 0.75 ; 95\% CI, 0.62-0.92). No significant heterogeneity was identified $\left(p=0.56 ; \mathrm{I}^{2}=\right.$ $0 \%)$. Seven $(95 \% \mathrm{CI}, 4-25)$ patients would require treatment with mild induced hypothermia to prevent 1 in-hospital death (Fig. 2).

All 4 studies reported neurologic outcome, and 3 of the 4 showed improved neurologic outcomes with mild hypothermia. ${ }^{28,30,31}$ Although different assessment scales were used in the trials, patients classified as having "good" neurologic outcomes were similar between studies. The HACA Study ${ }^{30}$ and the Hachimi-Idrissi and coworkers study ${ }^{29}$ used the Glasgow-Pittsburgh Cerebral Performance category to determine neurologic status. Good neurologic outcome was defined as 1 (good recovery) or 2 (moderate disability), and poor outcome was defined as a Cerebral Performance Category of 3 (severe disability), 4 (vegetative state) or 5 (death). Mori and associates ${ }^{28}$ used the Glasgow Outcome Scale, with good neurologic outcome being moderate, mild, or no disability. The Bernard and colleagues study ${ }^{31}$ assessed outcome based on discharge loca- 
tion, with those being discharged home or to a rehabilitation facility as having a good outcome, and those being discharged to a long-term nursing facility or death as having a poor outcome. Overall, mild induced hypothermia reduced pooled incidence of poor neurologic outcome compared with treatment with normothermia (RR, 0.74; 95\% CI, 0.62-0.84). There was moderate heterogeneity in these data $\left(p=0.11 ; \mathrm{I}^{2}=51.0 \%\right)$. Overall, $5(95 \% \mathrm{CI}, 4-10)$ patients would require treatment with mild induced hypothermia to prevent one additional poor neurologic outcome (Fig. 3).

Treatment-limiting adverse events were not consistently reported across all 4 studies. Three reported only bleeding and lethal or long-lasting arrythmias, ${ }^{29-31}$ and 2 reported sepsis $^{30,31}$ and hemodynamic instability (based on mean arterial pressure). ${ }^{29,31}$ Although 1 study reported a trend toward higher sepsis rates in the hypothermia group,,$^{30}$ this difference was not statistically significant. There were no other differences in rates of adverse events.

Sensitivity analysis based on random effects versus fixed effects modelling and elimination of studies with Jadad scores less than 3 yielded similar results with no change in the direction or the statistical significance of outcomes.

\section{Discussion}

The International Liaison Committee on Resuscitation ${ }^{32}$ and the Canadian Association of Emergency Physicians Critical Care Committee ${ }^{33-35}$ have recommended mild hypothermia be considered for select cardiac arrest patients who are comatose after ROSC. Others have recommended the earliest possible initiation of cooling after ROSC, and some data suggests that pre-hospital cooling is feasible.

Despite these recommendations, a recent survey ${ }^{36}$ of practising US emergency physicians, critical care physicians and cardiologists showed that $87 \%$ of respondents had never used hypothermia following cardiac arrest. The main reasons cited for not inducing mild hypothermia were insufficient data, treatment not mentioned in Advanced Cardiac Life Support protocols and technical difficulties related to cooling. As the HACA Study ${ }^{30}$ only en-

\begin{tabular}{|c|c|c|}
\hline Study & $\begin{array}{c}\text { Jadad Scale } \\
\text { score* }\end{array}$ & $\begin{array}{c}\text { Cochrane } \\
\text { gradet }\end{array}$ \\
\hline HACA Group 30 & 3 & $A$ \\
\hline Bernard et $\mathrm{al}^{31}$ & 1 & C \\
\hline Hachimi-Idrissi et al $^{29}$ & 3 & A \\
\hline Mori et $\mathrm{al}^{28}$ & 1 & B \\
\hline \multicolumn{3}{|c|}{$\begin{array}{l}\text { *Jadad Scale (0-5) determines quality of clinical trials based on } \\
\text { study randomization, presence of double-blinding, description } \\
\text { of withdrawals and process of randomization and blinding. } \\
\text { tCochrane approach assesses allocation concealment using the } \\
\text { following principles: grade A, adequate concealment; } B \text {, } \\
\text { uncertain concealment; C, clearly inadequate concealment. }\end{array}$} \\
\hline
\end{tabular}

Table 1. Comparison of the 4 randomized controlled trials included in the systematic review

\begin{tabular}{|c|c|c|c|c|c|c|c|c|c|}
\hline \multirow{2}{*}{$\begin{array}{l}\text { Study } \\
\text { (total } \\
\text { no. of } \\
\text { patients) }\end{array}$} & \multirow[b]{2}{*}{$\begin{array}{l}\text { Presenting } \\
\text { cardiac } \\
\text { rhythm }\end{array}$} & \multicolumn{6}{|c|}{ Hypothermia group } & \multicolumn{2}{|c|}{ Control group } \\
\hline & & $\begin{array}{l}\text { Method } \\
\text { of cooling }\end{array}$ & Goal temp & $\begin{array}{c}\text { Time to } \\
\text { goal } \\
\text { temp }\end{array}$ & $\begin{array}{c}\text { Duration } \\
\text { of } \\
\text { cooling }\end{array}$ & $\begin{array}{c}\text { In- } \\
\text { hospital } \\
\text { mortality }\end{array}$ & $\begin{array}{c}\text { Poor } \\
\text { neurologic } \\
\text { outcome }\end{array}$ & $\begin{array}{c}\text { In- } \\
\text { hospital } \\
\text { mortality }\end{array}$ & $\begin{array}{c}\text { Poor } \\
\text { neurologic } \\
\text { outcome }\end{array}$ \\
\hline $\begin{array}{l}\text { HACA } \\
\text { Group }^{30} \\
(n=275)\end{array}$ & $\begin{array}{l}\text { VF or } \\
\text { pulseless } \\
\text { VT }\end{array}$ & $\begin{array}{l}\text { Cooling } \\
\text { mattress } \\
\text { (plus ice } \\
\text { packs as } \\
\text { needed) }\end{array}$ & $\begin{array}{l}\text { Bladder } \\
\text { temp } \\
32^{\circ} \mathrm{C}-34^{\circ} \mathrm{C} \\
\leq 4 \mathrm{~h} \text { after } \\
\text { ROSC }\end{array}$ & $\begin{array}{l}6 \mathrm{~h} \text { after } \\
\text { initiation } \\
\text { of cooling }\end{array}$ & $24 \mathrm{~h}$ & $50 / 137$ & $61 / 136$ & $69 / 138$ & $83 / 137$ \\
\hline $\begin{array}{l}\text { Bernard } \\
\text { et } \mathrm{al}^{31} \\
(n=77)\end{array}$ & VF & Ice packs & $\begin{array}{l}\text { Tympanic/ } \\
\text { bladder } \\
\text { temp } 33^{\circ} \mathrm{C} \\
\leq 2 \mathrm{~h} \text { after } \\
\text { ROSC }\end{array}$ & $\begin{array}{l}2 \mathrm{~h} \text { after } \\
\text { ROSC }\end{array}$ & $12 \mathrm{~h}$ & $22 / 43$ & $22 / 43$ & $23 / 34$ & $25 / 34$ \\
\hline $\begin{array}{l}\text { Hachimi- } \\
\text { Idrissi } \\
\text { et } \text { al }^{29} \\
(n=30)\end{array}$ & $\begin{array}{l}\text { Asystole } \\
\text { or PEA }\end{array}$ & $\begin{array}{l}\text { Cooling } \\
\text { helmet }\end{array}$ & $\begin{array}{l}\text { Bladder } \\
\text { temp } 34^{\circ} \mathrm{C} \\
\leq 4 \mathrm{~h} \text { after } \\
\text { initiation } \\
\text { of cooling }\end{array}$ & $\begin{array}{l}3 \mathrm{~h} \text { after } \\
\text { initial } \\
\text { cooling }\end{array}$ & $0 \mathrm{~h}$ & $13 / 16$ & $14 / 16$ & $13 / 14$ & $14 / 14$ \\
\hline $\begin{array}{l}\text { Mori et } \mathrm{al}^{28} \\
(n=54)\end{array}$ & Unknown & Unknown & $32^{\circ} \mathrm{C}-34^{\circ} \mathrm{C}$ & Unknown & 3 days & N/A & $18 / 36$ & N/A & $16 / 18$ \\
\hline
\end{tabular}


rolled $8 \%$ of their patients initially assessed for study eligibility, the generalizability of mild hypothermia to all patients with cardiac arrest has also been questioned.

This systematic review sought to compile data from all relevant literature concerning the use of mild hypothermia in comatose post cardiac arrest survivors. Despite differences in cooling protocols between the studies, the pooled results demonstrate that mild hypothermia is associated with statistically significant and clinically important decreases in hospital mortality and improvements in neurologic outcome. Mild hypothermia was also successfully induced within 2-6 hours of external cooling in the 3 studies which reported this variable. ${ }^{29-31}$ Although not uniformly reported across all studies, mild hypothermia did not significantly increase adverse events. As with any systematic review, the reported incidence of side effects must be viewed with caution.

Clearly, sudden cardiac arrest is common and carries a dismal prognosis. In those patients for whom resuscitation is attempted, less than $10 \%$ survive to hospital discharge, ${ }^{37-39}$ and less than $50 \%$ of discharged patients are neurologically intact. ${ }^{40}$ Brain death or limitation of active treatment is often the cause of patient demise. ${ }^{41}$ Currently, the standard of care for primary cardiac arrest patients who remain comatose after ROSC involves supportive care and serial neurologic examination to determine prognosis. ${ }^{42}$

The pathophysiology of ischemic neuronal injury is incompletely understood but is thought to occur through a myriad of mechanisms, including release of excitatory neurotransmitters, dysregulation of calcium homeostasis, and free radical oxidation of cellular components. ${ }^{43,44}$ Anoxic brain injury, although related to the length of no circulation time, is an ongoing process after ROSC..$^{37,41,43-45}$ Hypothermia is thought to play a neuroprotective role after ROSC by decreasing metabolic demand ${ }^{46,47}$ decreasing the release of excitatory neurotransmitters, ${ }^{16}$ and decreasing inflammation. ${ }^{48}$

Animal studies since the $1980 \mathrm{~s}^{49-57}$ have suggested that mild induced hypothermia may be beneficial as a neuroprotectant after cardiac arrest. In addition, human literature describes a beneficial effect of mild induced hypothermia in resuscitated post cardiac arrest patients. ${ }^{58,59}$ However, there is concern that core temperature reduction may be associated with increased rates of hemodynamic instability, ${ }^{19}$ coagulopathy, ${ }^{20,21}$ and immune deficiency, therefore resulting in increased rates of sepsis ${ }^{17,18}$ and pneumonia. ${ }^{60}$

Multiple complications were assessed by the included studies, and there was no adverse event consistently associ-

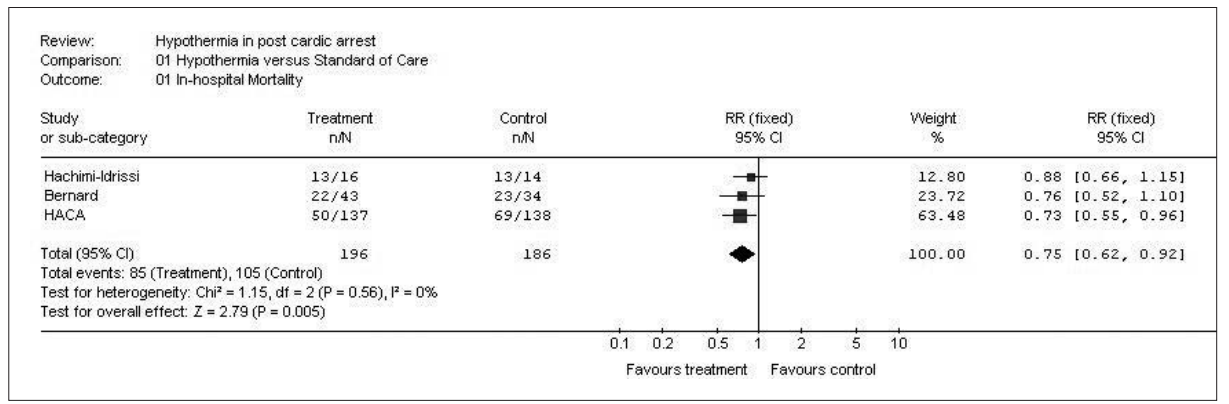

Fig. 2. Comparison of in-hospital mortality between patients treated with mild hypothermia and the control group. $\mathbf{R R}=$ relative risk; $\mathrm{Cl}=$ confidence interval; $\mathbf{d f}=$ degrees of freedom; Hachimi-Idrissi = Hachimi-Idrissi et $\mathrm{al}^{29}$; Bernard = Bernard et $\mathrm{al}^{31}$; HACA = Hypothermia after Cardiac Arrest Study 30

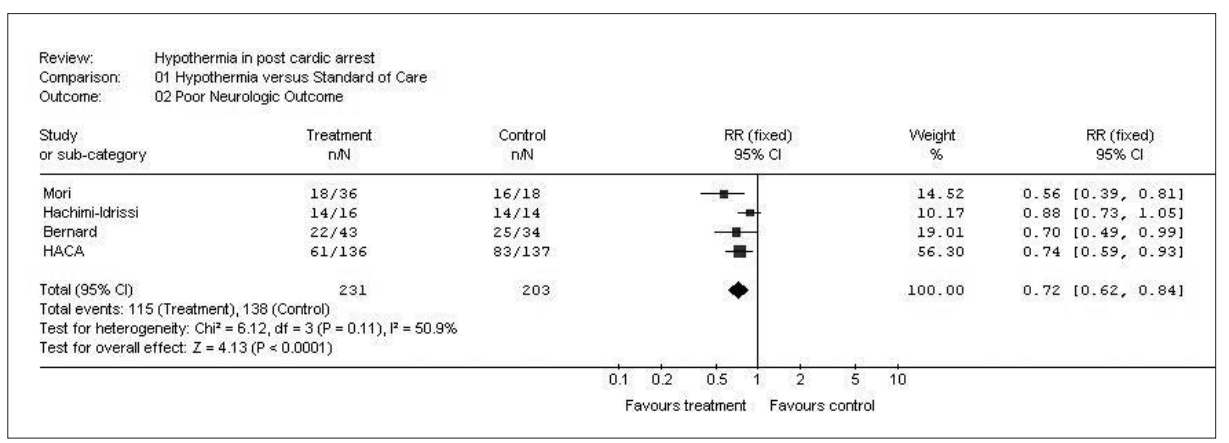

Fig. 3. Comparison of neurologic outcome between patients treated with mild hypothermia and the control group. See Fig. 2 for legend; plus, Mori = Mori et al. ${ }^{28}$ 
ated with hypothermia. The Bernard and colleagues study ${ }^{31}$ demonstrated a statistically significant increase in the incidence of hyperglycemia in the hypothermia group. Although hyperglycemia has been suggested to cause additional neurologic damage in a carotid artery occlusion study on rats, ${ }^{61}$ this was not the case in the Bernard and colleagues study. In the Hachimi-Idrissi and coworkers study, ${ }^{29}$ enrolled patients had either PEA or asystolic arrest, and the majority did not survive. It is possible that these patients did not live long enough to develop complications associated with hypothermia treatment. However, patients in the hypothermia group did have lower $\mathrm{O}_{2}$ extraction ratios and lower lactate levels. This has been seen in multiple other hypothermia studies, ${ }^{10,11,47,62}$ indicating that at least some commonly seen effects of hypothermia were present, despite the short duration of cooling. No specific biochemical aberrations were demonstrated in this study.

\section{Limitations}

This systematic review is a comprehensive analysis of the available literature. However, the results are dominated by the HACA Study ${ }^{30}$ due to the large number of patients enrolled. The Bernard and colleagues, ${ }^{31}$ HACA, and Mori and associates ${ }^{28}$ studies all showed improved neurologic outcome with mild hypothermia. However, the HACA Study was the only one that showed a statistically significant decrease in mortality. Furthermore, differences in cooling procedures and duration limit our ability to comment on the optimal method, rate and duration of induced hypothermia. There are inadequate data to comment on potential rates of complications with mild hypothermia. Finally, the 2 largest studies in this review only included patients with unstable ventricular arrhythmias.

There is a possibility of publication bias in this review. By missing unpublished "statistically" negative trials, it is possible to overestimate the treatment effect; however, a comprehensive search of the published literature for potentially relevant studies was conducted, using a systematic strategy to avoid bias. This was followed by contacts with corresponding and first authors. Although no unpublished or negative trials were identified, we recognize that these types of trials may exist. In addition, the funnel plot demonstrates asymmetry, its capacity to detect bias is limited when only a limited number of small trials are included in a meta-analyses. Given the nature of this research (e.g., expensive, complex, difficult to fund), these small negative trials are unlikely and would not be expected to influence the results.

There is also the possibility of study selection bias. However, we employed 2 independent reviewers and feel confident that the studies excluded were done so for consistent and appropriate reasons. Our search was comprehensive and has been updated, so it is unlikely that we missed any published trials.

With respect to the pooling of data, "moderate" heterogeneity was identified for neurologic outcome. However, the $\chi^{2}$ test for heterogeneity was not statistically significant. Although the trials included in this systematic review differ somewhat, they are sufficiently similar in their populations studied, interventions, outcomes and design to warrant pooling of data. Visual inspection of the Forrest plot for neurologic outcome (Fig. 3) reveals that all of the $95 \%$ CIs of the individual trials overlap and that the point estimates all favour treatment, making for "visual homogeneity."

This review demonstrates a clinically significant improvement in neurologic outcome and decrease in mortality in post cardiac arrest comatose patients treated with mild hypothermia. The findings of a recent individual patient data meta-analysis on induced hypothermia after cardiac arrest also showed a benefit of mild hypothermia on neurologic outcome and mortality. ${ }^{63}$ The study by Mori and associates, ${ }^{28}$ which met their inclusion criteria but was only available in abstract form, was not included. Further research is required to determine which patients will receive the greatest benefit from mild hypothermia as the discussed studies included patients with varying presenting cardiac rhythms. The optimal method and duration of inducing hypothermia are yet to be determined. Finally, legitimate concerns regarding the incidence of treatment limiting side-effects such as sepsis and hemorrhage require further investigation.

\section{Competing interests: None declared.}

Acknowledgements: We thank Mr. Tim Ruggles for assistance with the literature search. We also acknowledge the assistance of the following authors of included studies: F. Sterz, S.A. Bernard, S. Hachimi-Idrissi, E. Dickson, and K. Mori. We also thank Dr. Brian Rowe, Canada Research Chair in Emergency Airway Diseases and Research Director, Department of Emergency Medicine, University of Alberta, for his advice on the manuscript.

\section{References}

1. World Health Organization. Cardiovascular Diseases - Prevention and Control. Geneva: The Organization; 2001.

2. Mayer SA. Hypothermia for neuroprotection after cardiac arrest. Curr Neurol Neurosci Rep 2002;2:525-6.

3. Myerburg RJ, Castellanos A. Heart disease: a textbook of cardiovascular medicine. 5th ed. Philadelphia: W.B. Saunders; 1997. 
4. Eisenberg MS, Horwood BT, Cummins RO, et al. Cardiac arrest and resuscitation: a tale of 29 cities. Ann Emerg Med 1990; 19:179-86.

5. Bernard SA. Outcome from prehospital arrest in Melbourne, Australia. Emerg Med 1998;10:25-9.

6. Randomized clinical study of thiopental loading in comatose survivors of cardiac arrest. Brain Resuscitation Clinical Trial I Study Group. N Engl J Med 1986;314(7):397-403.

7. A randomized clinical study of a calcium-entry blocker (lidoflazine) in the treatment of comatose survivors of cardiac arrest. Brain Resuscitation Clinical Trial II Study Group. N Engl J Med 1991;324(18):1225-31.

8. Roine RO, Kaste M, Kinnunen A, et al. Nimodipine after resuscitation from out-of-hospital ventricular fibrillation. A placebocontrolled, double-blind, randomized trial. JAMA 1990;264: 3171-7.

9. Jastremski M, Sutton-Tyrrell K, Vaagenes P, et al. Glucocorticoid treatment does not improve neurological recovery following cardiac arrest. Brain Resuscitation Clinical Trial I Study Group. JAMA 1989;262:3427-30.

10. Chopp M, Knight R, Tidwell CD, et al. The metabolic effects of mild hypothermia on global cerebral recirculation in the cat: a comparison to normothermia and hyperthermia. J Cereb Blood Flow Metab 1989;9:141-8.

11. Xue D, Huang ZG, Smith KE, et al. Immediate or delayed mild hypothermia prevents focal cerebral infarction. Brain Res 1992; 587(1):66-72.

12. Bernard S. Induced hypothermia in intensive care medicine. Anaesth Intensive Care 1996;24:382-8.

13. Hegnauer AH, D'Amato HE. Oxygen consumption and cardiac output in the hypothermic dog. Am J Physiol 1954;178:138-42.

14. Morimoto Y, Kemmotsu O, Kitami K, et al. Acute brain swelling after out-of-hospital cardiac arrest: pathogenesis and outcome. Crit Care Med 1993;21:104-10.

15. Callaway CW, Tadler SC, Katz LM, et al. Feasibility of external cranial cooling during out-of-hospital cardiac arrest. Resuscitation 2002;52:159-65.

16. Busto R, Globus MYT, Dietrich WD, et al. Effect of mild hypothermia on ischemia-induced release of neurotransmitters and free fatty acids in rat brain. Stroke 1989;20:904-10.

17. Biggar WD, Bohn DJ, Kent G. Neutrophil circulation and release from bone marrow during hypothermia. Infect Immun 1983;40:708-12.

18. Bohn DJ, Biggar WD, Smith CR, et al. Influence of hypothermia, barbiturate therapy, and intracranial pressure monitoring on morbidity and mortality after near drowning. Crit Care Med 1986;14:529-34.
19. Yanagawa $\mathrm{Y}$, Ishihara $\mathrm{S}$, Norio $\mathrm{H}$, et al. Preliminary clinical outcome study of mild resuscitative hypothermia after out-ofhospital cardiopulmonary arrest. Resuscitation 1998;39:61-6.

20. Rohrer MJ, Natale AM. Effect of mild hypothermia on the coagulation cascade. Crit Care Med 1992;20:1402-5.

21. Valeri CR, Feingold H, Cassidy G, et al. Hypothermia-induced reversible platelet dysfunction. Ann Surg 1987;205:175-81.

22. Landis JR, Koch GG. The measurement of observer agreement for categorical data. Biometrics 1977;33:159-74.

23. Clarke M, Oxman AD, eds. Cochrane reviewers' handbook 4.2.0. Oxford: Update Software; 2003.

24. Jadad AR, Moore RA, Carroll D, et al. Assessing the quality of reports of randomized clinical trials: is blinding necessary? Cont Clin Trials 1996;17:1-12.

25. Higgins JP, Thompson SG, Deek JJ, et al. Measuring inconsistency in meta-analyses. BMJ 2003;327:557-60.

26. Breslow NE, Day NE. Analysis of case-control studies. Statistical methods in cancer research. Lyon: International Agency for Research on Cancer; 1980.

27. Egger M, Davey Smith G, Schneider M, et al. Bias in meta-analysis detected by a simple graphical test. BMJ 1997;325:629-34.

28. Mori K, Takeyama Y, Itoh Y, et al. Multivariate analysis of prognostic factors in survivors of out-of-hospital cardiac arrest with brain hypothermia therapy. Crit Care Med 2000;28:A168.

29. Hachimi-Idrissi S, Corne L, Ebinger G, et al. Mild hypothermia induced by a helmet device: a clinical feasibility study. Resuscitation 2001;51:275-81.

30. Hypothermia after Cardiac Arrest Study Group. Mild therapeutic hypothermia to improve the neurologic outcome after cardiac arrest [published erratum appears in N Engl J Med 2002;346 (22):1756]. N Engl J Med 2002;346(8):549-56.

31. Bernard SA, Gray TW, Buist MD, et al. Treatment of comatose survivors of out-of-hospital cardiac arrest with induced hypothermia. N Engl J Med 2002;346:557-63.

32. Nolan JP, Morley MD, Vanden Hoek TL, et al. Therapeutic hypothermia after cardiac arrest. An advisory statement by the advanced life support task force of the International Liaison Committee on Resuscitation. Resuscitation 2003;57:231-5.

33. Green RS, Howes D; on behalf of the CAEP Critical Care Committee. Hypothermic modulation of anoxic brain injury in adult survivors of cardiac arrest: a review of the literature and an algorithm for emergency physicians. Can J Emerg Med 2005;7(1): 42-7.

34. Canadian Association of Emergency Physicians (CAEP) and the CAEP Critical Care Committee. Guidelines for the use of hypothermia after cardiac arrest [position statement]. Can J Emerg Med 2006;8(2):106-8. 
35. Howes D, Green R, Gray S, et al; for the Canadian Association of Emergency Physicians. Evidence for the use of hypothermia after cardiac arrest. Can J Emerg Med 2006;8(2):109-15.

36. Abella BS, Rhee JW, Huang KN, et al. L.B B. Induced hypothermia is underused after resuscitation from cardiac arrest: a current practice survey. Resuscitation 2005;64:181-6.

37. Callaway CW. Improving neurologic outcomes after out-of-hospital cardiac arrest. Prehosp Emerg Care 1997;1:45-57.

38. Stiell IG, Wells GA, Field B, et al. Ontario Prehospital Advanced Life Support Study Group. Advanced Cardiac Life Suppport in Out-of-Hospital Cardiac Arrest. N Engl J Med 2004;351:647-56.

39. Vaillancourt C, Stiell IG. Canadian Cardiovascular Outcomes Research Team. Cardiac arrest care and emergency medical services in Canada. Can J Cardiol 2004;20:1081-90.

40. Richmond TS. Cerebral resuscitation after global brain ischemia: linking research to practice. AACN Clin Issues 1997;8 (2):171-81.

41. Krause GS, Kumar K, White BC, et al. Ischemia, resuscitation, and reperfusion: meachanisms of tissue injury and prospects for protection. Am Heart J 1986;111:768-80.

42. Attia J, Cook D. Prognosis in anoxic and traumatic coma. Crit Care Clin 1998;14:497-511.

43. Bulkley GB. Reactive oxygen metabolites and reperfusion injury: Aberrant triggering of reticuloendothelial function. Lancet 1994;344:934-6.

44. White BC, Sullivan JM, DeGracia DJ, et al. Brain ischaemia and reperfusion: molecular mechanisms of neuronal injury. J Neurol Sci 2000;179:1-33

45. Negovsky VA. Postresuscitation disease. Crit Care Med 1988; 16:942-6.

46. Laptook AR, Corbett RJ, Sterett R, et al. Quantitative relationship between brain temperature and energy utilization rate measured in vivo using $31 \mathrm{P}$ and $1 \mathrm{H}$ magnetic resonance spectroscopy. Pediatr Res 1995;38:919-25.

47. Michenfelder JD, Milde JH. The relationship among canine brain temperature, metabilism, and function during hypothermia. Anesthesiology 1991;75:130-6.

48. Nandate K, Vuylsteke A, Crosbie AE, et al. Cerebrovascular cytokine responses during coronary artery bypass surgery: specific production of interleukin- 8 and its attenuation by hypothermic cardiopulmonary bypass. Anesth Analg 1999;89:823-8.

49. Xiao F, Safar P, Alexander H. Peritoneal cooling for mild hypothermia after cardiac arrest in dogs. Resuscitation 1995;30:51-9.

50. Sterz F, Safar P, Tisherman SA, et al. Mild hypothermic car- diopulmonary resuscitation improves outcome after prolonged cardiac arrest in dogs. Crit Care Med 1991;19:379-89.

51. Brader E, Jehle D, Safar P. Protective head cooling during cardiac arrest in dogs [abstract]. Ann Emerg Med 1985;14:510.

52. Marion DW, Leonov Y, Ginsberg M, et al. Resuscitative hypothermia. Crit Care Med 1996;24(suppl.):S81-9.

53. Weinrauch V, Safar P, Tisherman SA, et al. Beneficial effect of mild hypothermia and detrimental effect of deep hypothermia after cardiac arrest in dogs. Stroke 1992;23:1454-62.

54. Kuboyama K, Safar P, Radovsky A, et al. Delay in cooling negates the beneficial effect of mild resuscitative cerebral hypothermia after cardiac arrest in dogs: a prospective, randomized study. Crit Care Med 1993;21:1348-58.

55. Illievich UM, Zornow MH, Choi KT, et al. Effects of hypothermic metabolic suppression on hippocampal glutamate concentrations after transient global cerebral ischemia. Anesth Analg 1994;78:905-11.

56. Hicks SD, DeFranco DB, Callaway CW. Hypothermia during reperfusion after asphyxial cardiac arrest improves functional recovery and selectively alters stress-induced protein expression. J Cereb Blood Flow Metab 2000;20:520-30.

57. Leonov Y, Sterz F, Safar P, et al. Mild cerebral hypothermia during and after cardiac arrest improves neurologic outcome in dogs. J Cereb Blood Flow Metab 1990;10:57-70.

58. Bernard SA, Jones BM, Horne MK. Clinical trial of induced hypothermia in comatose survivors of out-of-hospital cardiac arrest. Ann Emerg Med 1997;30:146-53.

59. Shirai S, Yokoi H, Kimura T, et al. Mild hypothermia for brain resuscitation after cardiac arrest. Circulation 2002;106:2011S.

60. Schubert A. Side effects of mild hypothermia. J Neurosurg Anesthesiol 1995;7:139-47.

61. Pulsinelli WA, Waldman S, Rawlinson D, et al. Moderate hyperglycemia augments ischemic brain damage: a neuropathologic study in the rat. Neurology 1982;32:1239-46.

62. Michenfelder JD, Theye RA. The effects of anesthesia and hypothermia on canine cerebral ATP and lactate during anoxia produced by decapitation. Anesthesiology 1970;33:430-9.

63. Holzer M, Bernard SA, Hachimi-Idrissi S, et al.; for the Collaborative Group on Induced Hypothermia for Neuroprotection After Cardiac Arrest. Hypothermia for neuroprotection after cardiac arrest: systematic review and individual patient data meta-analysis. Crit Care Med 2005;33:414-8.

Correspondence to: Dr. Robert Green, Division of Critical Care, Queen Elizabeth II Health Sciences Centre, Dalhousie University, 1278 Tower Rd., Rm. 349, Bethune Building, Halifax NS B3H 2 Y9 